\title{
KNOWLEDGE AND SELF-CARE PRACTICES AMONG DIABETICS
}

\author{
SHEEBA ${ }^{1 *}{ }^{*}$, SNEHA AK ${ }^{2}$, VEENA BIJU ${ }^{2}$ \\ ${ }^{1}$ Department of Community Health Nursing, Amrita College of Nursing, Amrita University, Kochi, Kerala, India. ${ }^{2}$ Nursing Student, Amrita \\ College of Nursing, Amrita University, Kochi, Kerala, India. Email: aswinprasadsheeba@gmail.com
}

Received: 01 July 2017, Revised and Accepted: 31 August 2017

ABSTRACT

Objective: The objectives of the study were to assess the knowledge and self-care practices among patients with type 2 diabetes mellitus.

Methods: Quantitative approach with descriptive survey design and convenience sampling technique was used. The study was conducted among 100 patients with type 2 diabetes mellitus, from the Inpatient and Outpatient Department of Amrita Institute of Medical Science, Kochi. A structured knowledge questionnaire and structured practice assessment questionnaire were used to assess the knowledge and self-care practices of the subjects.

Result: Result shows that $77 \%$ subjects had good knowledge regarding diabetes and majorityof the subjects had good level of self-care practices. $63 \%$ of subjects regularly monitoring blood glucose level, $72 \%$ following proper diet, $88 \%$ of subjects taking regular medication, $84 \%$ of subjects follow proper eye care, $79 \%$ of subjects follow proper foot care, $57 \%$ of subjects maintaining ideal body weight, and only $46 \%$ of subjects doing regular exercise. There was a positive relationship ( $\mathrm{r}=0.09)$ between level of knowledge and self-care practice of the subjects and no significant association between knowledge level and selected sociodemographic variables.

Conclusion: It is important that the patient should have adequate knowledge regarding diabetes and they should follow proper self-care practices to prevent further complications.

Keywords: Knowledge, Self-care practices, Type 2 diabetes mellitus.

(C) 2017 The Authors. Published by Innovare Academic Sciences Pvt Ltd. This is an open access article under the CC BY license (http://creativecommons. org/licenses/by/4. 0/) DOI: http://dx.doi.org/10.22159/ajpcr.2017.v10i12.21072

\section{INTRODUCTION}

Diabetes is a group of metabolic disorder characterized by hyperglycemia resulting from defects in insulin secretion, insulin action, or both. It is associated with damage, dysfunction, and failure of different organs, especially the eyes, kidneys, nerves, heart, and blood vessels. The major classification of diabetes is types 1 and 2, gestational diabetes and diabetes associated with the syndrome. Type 1 diabetes accounts for only $5-10 \%$ of those with diabetes, previously encompassed by the term insulin-dependent diabetes or juvenile-onset diabetes, results from a cell-mediated autoimmune destruction of the $\beta$-cells of the pancreas. Type 2 diabetes accounts for $90-95 \%$ of those with diabetes, previously referred to as noninsulin-dependent diabetes or adult-onset diabetes encompasses individuals who have insulin resistance and usually have relative (rather than absolute) insulin deficiency [1].

Globally, an estimated 422 million adults were living with diabetes in 2014, compared to 108 million in 1980. The global prevalence (age-standardized) of diabetes has nearly doubled since 1980, rising from $4.7 \%$ to $8.5 \%$ of the adult population. Over the past decade, diabetes prevalence has risen faster in low- and middle-income countries than in high-income countries. Diabetes caused 1.5 million deaths in 2012 [2].

India is one of the six countries of the IDF SEA region. 415 million people have diabetes in the world and 78 million people in the SEA Region; by 2040 this will rise to 140 million. There were 69.1 million cases of diabetes in India in 2015. One in three or 33\% of Indians over 30 years of age is suffering from one or more lifestyle diseases such as diabetes, high cholesterol, blood pressure, thyroid, and cancer [3].

The foundation of diabetes management is diet, insulin, and oral medication. Patient education and self-care practices are also important aspects of disease management that help people with diabetes to lead a normal life. To survive, people with type 1 diabetes must have insulin delivered by injection or a pump. But people with type 2 diabetes can control their blood glucose by following a healthy meal plan and exercise program, losing excess weight, and taking oral medication. Some people with type 2 diabetes may need insulin to control their blood glucose [4].

Oral hypoglycemic agents such as sulfonylureas and biguanides are still the major players in the management of the disease, but there is growing interest in herbal remedies due to the side effects associated with the oral hypoglycemic agents. Herbal medicines have been a highly esteemed source of medicine throughout the human history. They are widely used today indicating that herbs are a growing part of modern high-tech medicine [5].

Conventional drug therapy though effective in the management of diabetes mellitus is expensive and has toxic side effects. Herbal medicine would thus provide alternative therapy if effective and less toxic [6].

Self-management education or training is a key step in improving health outcomes and quality of life. It focuses on self-care behaviors such as healthy eating, being active, and monitoring blood sugar. It is a collaborative process in which diabetes educators help people with or at risk for diabetes gain the knowledge and problem-solving and coping skills needed to successfully self-manage the disease and its related conditions [4].

An observational prospective study was conducted among 115 patients with type 2 diabetes mellitus who are failing with oral antidiabetic medication and visits to the diabetes clinic. The diabetes quality of life clinical trial questionnaire (DQLCTQ) was used to assess health-related quality of life in patients with type 2 diabetes mellitus at baseline and 3 month follow-up period. For each patient, data were collected on the duration of diabetes, treatment regimen, level of glycemic control, and presence of complications through medical records. The result revealed 
that no significant association between disease duration with DQLCTQ score. These findings suggest that treatment regimen, level of glycemic control, and the presence of complications are associated with quality of life [7]

A cross-sectional study was conducted to establish the level of knowledge of diabetes among community members in rural and urban areas of Kenya and determine the impacts of attitudes and practices toward diabetes. Result of the study revealed that the level of knowledge, attitude, and practice of the members regarding diabetes was poor [8].

A descriptive study was conducted to assess the knowledge, attitudes, and practices among 100 patients with type 2 diabetic in Abbottabad. They concluded that the knowledge, attitude and practice scores were low and in most areas of diabetes care emphasizing the need for additional educational efforts [9].

A study was conducted to determine the knowledge level and medication adherence level among 147 in-patients aged 60 years old and above who had been received treatment for type 2 diabetes mellitus. The result revealed that majority of the geriatric participant possessed high levels of knowledge of their medication and disease (53.7\%). Their medication adherence was high (66\%). The knowledge score was found to be significantly decreased by the increasing age and lower educational levels. Medication adherence score was increasing significantly with increasing age. It was concluded that an effective diabetic education could improve the knowledge and medication adherence among geriatric patients [10].

A descriptive cross-sectional study was conducted to assess knowledge and self-care practices among 110 type 2 diabetics, Visakhapatnam. The study concluded that there is a need to promote self-care practices among the diabetic patients and integrate all the components of self-care education in clinical practice for a better outcome in the management of diabetes [11].

A cross-sectional survey was conducted among 507 patients with type 2 diabetes in a tertiary care hospital to assess the relationships between personal, disease and treatment-related factors and diabetes control. The findings suggest that health-care delivery inputs, patients' personal characteristics, including education and attitude, and family support for care are complexly processed to determine patients' ability to manage their disease, which ultimately influences disease [12].

A study was conducted to assess the relationship between knowledge, attitude, and practice on diabetic foot care between diabetic patients with and without diabetic foot ulcer; and the risk factors associated with diabetic foot ulcer. It was concluded that an inverse relationship between diabetic foot ulcer and foot care knowledge as well as practice was observed. Apart from tight glycemic control, diabetic patients must be educated and motivated on proper foot care practice and lifestyle modifications for preventing diabetic foot ulcer [13].

In current practice, most patients with diabetes mellitus visit the healthcare system when they have any health issue. A few people may come for regular follow-up. Assessment is the first step to identify the gap between knowledge and self-care practices. Hence, the investigators felt that it is important to assess the knowledge and self-care practices among patients with type 2 diabetes admitted in AIMS, Kochi.

\section{METHODS}

The study was conducted among 100 patients with type 2 diabetes mellitus of AIMS, Kochi. Subjects were selected using non-probability convenient sampling technique. A descriptive survey design was used in this study. The setting was selected because of the easy accessibility of the group, familiarity with setting, convenience in terms of adequate sample and the cooperation offered by the management. The researcher explained the purpose of the study and obtained an informed consent from each subject. Structured knowledge questionnaire and structured practice assessment questionnaire were used to assess the knowledge and self-care practices of subjects, respectively. Data analysis was performed using descriptive and inferential statistics.

\section{RESULT}

Section I: Description of sociodemographic variables of the subjects

The data presented in Table 1 summarizes that $47 \%$ subjects were 60 years and above, $60 \%$ were male, $46 \%$ have primary education, most of the subjects were retired $31 \%$, and unemployed $34 \% .53 \%$ of the subjects have monthly income <Rs.10000/-, 61\% subjects from a rural area. 54\% subjects are having a family history of type 2 diabetes mellitus. Most of the subjects (42\%) were experiencing diabetes more than 10 years, and $94 \%$ subjects are under control measures such as insulin (35\%), OHA (34\%) and combination (25\%), and only $6 \%$ of subjects are on diet control.

Section II: Description of knowledge level of subjects on diabetes The data depicted in Fig. 1 shows that among 100 subjects majority $(77 \%)$ had a good level of knowledge on diabetes.

Table 1: Frequency and percentage distribution of subjects based on demographic characteristics $n=100$

\begin{tabular}{|c|c|}
\hline Sample characteristics & Frequency $(\%)$ \\
\hline \multicolumn{2}{|l|}{ Age (years) } \\
\hline $30-39$ & $6(6.0)$ \\
\hline $40-49$ & $12(12.0)$ \\
\hline $50-59$ & $35(35.0)$ \\
\hline Above 60 & $47(47.0)$ \\
\hline \multicolumn{2}{|l|}{ Gender } \\
\hline Male & $60(60.0)$ \\
\hline Female & $40(40.0)$ \\
\hline \multicolumn{2}{|l|}{ Education } \\
\hline Primary & $46(46.0)$ \\
\hline Secondary & $33(33.0)$ \\
\hline Graduate & $18(18.0)$ \\
\hline Postgraduate & $3(3.0)$ \\
\hline \multicolumn{2}{|l|}{ Occupation } \\
\hline Government employee & $13(13.0)$ \\
\hline Self-employed & $33(22.0)$ \\
\hline Retired & $31(31.0)$ \\
\hline Unemployed & $34(34.0)$ \\
\hline \multicolumn{2}{|l|}{ Income } \\
\hline$<10000$ & $53(53.0)$ \\
\hline $10001-15000$ & $20(20.0)$ \\
\hline $15001-20000$ & $10(10.0)$ \\
\hline$>20000$ & $17(17.0)$ \\
\hline \multicolumn{2}{|l|}{ Area of residence } \\
\hline Urban & $38(38.0)$ \\
\hline Rural & $61(61.0)$ \\
\hline Others & $1(1.0)$ \\
\hline \multicolumn{2}{|c|}{ Family history of type 2 diabetes } \\
\hline Father & $18(18.0)$ \\
\hline Mother & $23(23.0)$ \\
\hline Grandparents & $10(10.0)$ \\
\hline Others & $3(3.0)$ \\
\hline No & $46(46.0)$ \\
\hline \multicolumn{2}{|l|}{ Duration of illness (year) } \\
\hline$<1$ & $10(10.0)$ \\
\hline $1-5$ & $25(25.0)$ \\
\hline $6-10$ & $23(23.0)$ \\
\hline$>10$ & $42(42.0)$ \\
\hline \multicolumn{2}{|l|}{ Control measures } \\
\hline Diet & $6(6.0)$ \\
\hline OHA & $34(34.0)$ \\
\hline Insulin & $35(35.0)$ \\
\hline Combination & $25(25.0)$ \\
\hline
\end{tabular}


Table 2: Association between knowledge on diabetes and selected demographic variables $n=100$

\begin{tabular}{|c|c|c|c|c|c|}
\hline \multirow[t]{3}{*}{ Demographic variable } & \multicolumn{5}{|l|}{ Knowledge } \\
\hline & \multirow{2}{*}{$\begin{array}{l}\text { Below average } \\
\text { f (\%) }\end{array}$} & \multirow{2}{*}{$\begin{array}{l}\text { Above average } \\
\mathrm{f}(\%)\end{array}$} & \multirow[t]{2}{*}{ Df } & \multirow{2}{*}{$\chi_{\text {value }}^{2}$} & \multirow[t]{2}{*}{ p value } \\
\hline & & & & & \\
\hline \multicolumn{6}{|l|}{ Age } \\
\hline$<50$ & $4(22.2)$ & $14(77.8)$ & 2 & $0.231^{\mathrm{NS}}$ & 0.891 \\
\hline $50-60$ & $9(25.7)$ & $26(74.3)$ & & & \\
\hline$>60$ & $10(21.3)$ & 37 (78.7) & & & \\
\hline \multicolumn{6}{|l|}{ Gender } \\
\hline Male & $15(25.0)$ & $45(75.0)$ & 1 & $0.339^{\mathrm{NS}}$ & 0.561 \\
\hline Female & $8(20.0)$ & $32(80.0)$ & & & \\
\hline \multicolumn{6}{|l|}{ Education } \\
\hline SSLC & $9(19.6)$ & 37 (18.4) & 1 & $0.567^{\mathrm{NS}}$ & 0.451 \\
\hline Above SSLC & $14(25.9)$ & $40(74.1)$ & & & \\
\hline \multicolumn{6}{|l|}{ Occupation } \\
\hline Employed & $13(19.7)$ & $53(80.3)$ & 1 & $1.196^{\mathrm{NS}}$ & 0.274 \\
\hline Unemployed & $10(29.4)$ & $24(70.6)$ & & & \\
\hline \multicolumn{6}{|l|}{ Income } \\
\hline$<10000$ & $10(18.9)$ & 43 (81.1) & 1 & $1.087^{\mathrm{NS}}$ & 0.297 \\
\hline$>10000$ & $13(27.7)$ & $34(72.3)$ & & & \\
\hline \multicolumn{6}{|l|}{ Family history } \\
\hline Yes & $14(25.9)$ & $40(74.1)$ & 1 & $0.567^{\mathrm{NS}}$ & 0.451 \\
\hline No & $9(19.6)$ & $37(80.4)$ & & & \\
\hline \multicolumn{6}{|l|}{ Duration (year) } \\
\hline$>1$ & $3(30.0)$ & $7(70.0)$ & 3 & $3.345^{\mathrm{NS}}$ & 0.341 \\
\hline $1-5$ & $8(32.0)$ & $17(68.0)$ & & & \\
\hline $6-10$ & $6(26.1)$ & 17 (73.9) & & & \\
\hline$>10$ & $6(14.3)$ & $36(85.7)$ & & & \\
\hline
\end{tabular}

$(p<0.05)$, NS: No significant

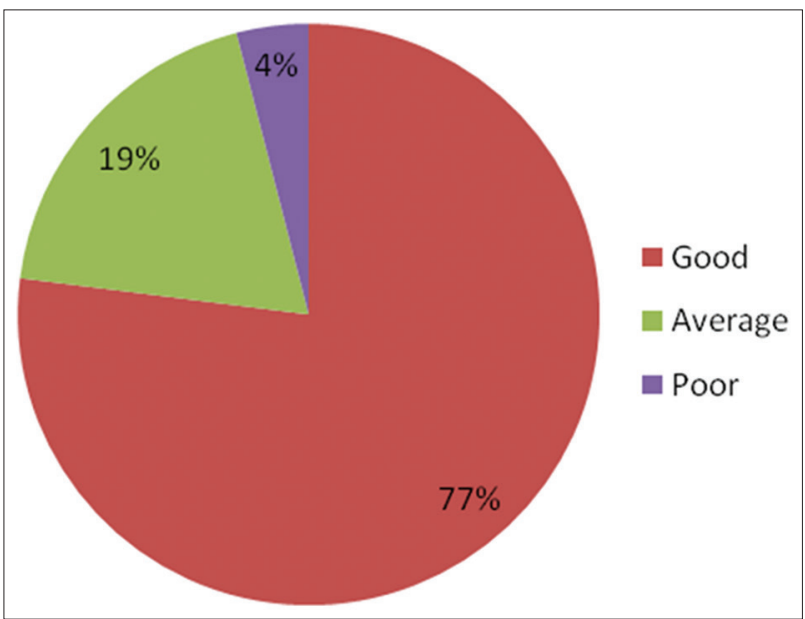

Fig. 1: Pie diagram showing percentage distribution of subject based on the knowledge level on diabetes

Section III: Description of self-care practices of subjects on diabetes

The data presented in Fig. 2 shows that majority of subjects had a good level of practices (63\%). Regularly monitoring blood glucose level, majority of subjects (72\%) following proper diet, $88 \%$ of subjects taking regular medication, $84 \%$ of subjects follows proper eye care, $79 \%$ of subjects follows proper foot care, $57 \%$ of subjects maintained ideal body weight and only $46 \%$ of subjects doing regular exercise.

Section IV: Association between knowledge and selected demographic variables

Data presented in Table 2 summarizes that there is no significant association between knowledge on diabetes and selected sociodemographic variables of subjects at 0.05 level of significance.

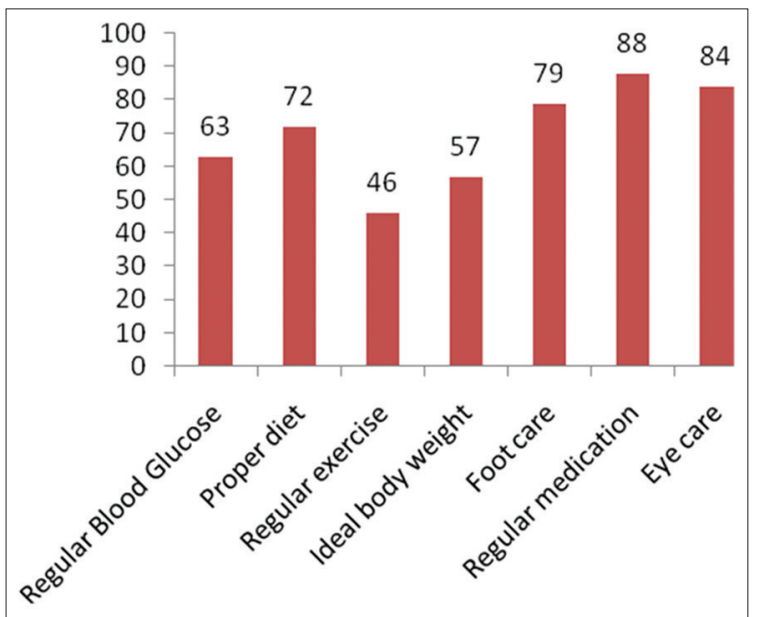

Fig. 2: Bar diagram showing percentage distribution of subject based on the self-care practices on diabetes

Section V: Correlation between knowledge and self-care practices of patients with type 2 diabetes mellitus

The data presented in Table 3 summarizres that there exists a positive correlation between knowledge and self-care practice of patients with type 2 diabetes mellitus. But the obtained $r=0.09$ is not statistically significant at 0.05 level with a corresponding $\mathrm{p}=0.359$.

\section{DISCUSSION}

In this study, $60 \%$ were male $47 \%$ subjects were 60 years and above $46 \%$ have primary education, most of the subjects were retired $31 \%$ and unemployed $34 \% .53 \%$ of the subjects have monthly income $<$ Rs.10000/-, 0.54\% subjects are having a family history of type 2 diabetes mellitus. Most of the subjects (42\%) were experiencing diabetes more than 10 years, and $94 \%$ subjects are under control measures such as insulin (35\%), OHA (34\%) and combination (25\%), and only $6 \%$ of subjects are on diet control. 
Table 3: Correlation of knowledge and self-care practice of patient with type 2 diabetes mellitus $n=100$

\begin{tabular}{lll}
\hline Variables & Karl-Pearson's r & p value \\
\hline Knowledge score & 0.09 & $0.359^{\mathrm{NS}}$ \\
Self-care practice score & & \\
\hline
\end{tabular}

NS: No significant

Similar study was conducted in Ethiopia shows that $57.7 \%$ were male, $69 \%$ were in the age group of $40-69$ years, $34.3 \%$ were unemployed, $57 \%$ had low monthly income, and all subjects are under control measures such as OHA (41.3\%) and insulin (58.7\%) [14].

The findings of the present study showed that majority of the subjects $(77 \%)$ had a good level of knowledge and self-care practices. Similar study was conducted in Visakhapatnam shows that knowledge regarding various activities such as performing regular physical activity, dietary modifications, and blood glucose monitoring are seen in $70.9 \%$, $72.72 \%$, and $74.54 \%$ of study participants, respectively [11].

A similar study was conducted in South Africa to assess the knowledge and self-care practices among 225 adults with diabetes shows that knowledge and practices related to diabetes among the participants were good in certain aspects [15].

\section{CONCLUSION}

It is important that the patient should have adequate knowledge regarding diabetes and they should follow proper self-care practice to prevent further complications.

\section{REFERENCES}

1. American Diabetes Association. Diagnosis and classification of diabetes mellitus. Diabetes Care 2010;33 Suppl 1:S62-9.

2. Global Report on Diabetes. World Health Organization. Geneva: World Health Organization; 2016.
3. International Diabetes Federation; 2015 Update. Diabetes Atlas. $7^{\text {th }}$ ed. Available from: https://www.idf.org/sites/default/files/Atlasposter-2015_EN.pdf.

4. Centres for Disease Control and Prevention. National Diabetes Fact sheet: National Estimates and General Information on Diabetes and Pre - Diabetes in the United States; 2012. Available from: http://www. cdc.gov/diabetes/pubs/pdf/ndfs_2011. [Last cited on 2012 Jan 20].

5. Rupeshkumar M, Kavitha K, Haldar PK. Role of herbal plants in the diabetes mellitus therapy: An overview. Int J Appl Pharm 2014;6:1-3.

6. Ngugi MP, Njagi MJ, Kibiti MC, Ngeranwa JN, Njagi NM, Njue M, et al. Herbal management of diabetes mellitus: A rapidly expanding research avenue. Int J Curr Pharm Res 2012;4(2):1-4.

7. Tri Murti A, Mohamed Izham MI, Ahmad HA. The association of diabetes related factor and quality of life in Type 2 diabetes mellitus. Int J Pharm Pharm Sci 2010;2(1):139-45.

8. Maina WK, Ndegwa ZM, Njenga EW, Muchemi EW. Knowledge, attitude, and practices related to diabetes among community members in four provinces in Kenya: A cross-sectional study. Afr J Diabetes Med 2011;19(1):15-8

9. Gul N. Knowledge, attitudes and practices of Type 2 diabetic patients. J Ayub Med Coll Abbottabad 2010;22(3):128-31.

10. Marhanis SO, Kong LS. Diabetes knowledge and medication adherence among geriatric patient with Type 2 diabetes mellitus. Int J Pharm Pharm Sci 2014;6(3):103-6.

11. Sarada V, Madhavi S, Madhavi DB. Knowledge and self care practices among Type II diabetics attending tertiary care hospital, Visakhapatnam City. RGUHS Natl J Public Health 2016;1(1):6-9.

12. Venkataraman K, Kannan AT, Kalra OP, Gambhir JK, Sharma AK, Sundaram KR, et al. Diabetes self-efficacy strongly influences actual control of diabetes in patients attending a tertiary hospital in India. J Commun Health 2012;37(3):653-2.

13. Chellan G, Srikumar S, Varma AK, Mangalanandan TS, Sundaram KR, Jayakumar RV, et al. Foot care practice - The key to prevent diabetic foot ulcers in India. Foot (Edinb) 2012;22(4):298-302.

14. Berhe KK, Gebru HB, Kahsay HB, Kahsay AA. Assessment of diabetes knowledge and its associated factors among Type 2 diabetic patients in mekelle and ayder referral hospitals, Ethiopia. J Diabetes Metab 2014;5(1):378

15. Mabaso RG, Oduntan OA. Knowledge and practices related to DM among adult with diabetes. Afr Vision Eye Health 2016;75(1):1-6. 